\title{
The glabella startle reflex: Inhibition by frequency and intensity modulations
}

\author{
JACQUELYN CRANNEY and MICHELLE E. COHEN \\ Bryn Mawr College, Bryn Mawr, Pennsylvania
}

\begin{abstract}
When a relatively weak stimulus, such as a mild tone, precedes a reflex-eliciting stimulus by an appropriate interval, the amplitude of the elicited reaction is reduced. Three experiments examined the relative impact of tonal frequency and intensity modulations, occurring prior to a glabella tap, on the amplitude of the elicited glabella reflex. Experiment 1 indicated that a frequency shift in an otherwise continuous pure tone yielded an amount of inhibition equivalent to that produced by a shift following an intensity decrement (i.e., gap) in the tone; further, this amount of inhibition was greater than that produced by a gap with no shift. Experiment 2 replicated this pattern of findings at two different tonal intensity levels, and showed that the lower tonal intensity led to less inhibition. Experiment 3 indicated that a 24-msec constant tonal frequency burst and a 24-msec shifting tonal frequency chirp presented prior to the glabella tap led to equivalent amounts of reflex inhibition; further, this amount of inhibition was not significantly different from that produced by a frequency shift, a gap, or a frequency shift coincidental with a gap.
\end{abstract}

Mammals subjected to an abrupt intense stimulus show widespread visceral and skeletal responses that constitute the startle reflex (Landis \& Hunt, 1939). In humans, a moderately intense tactile stimulus applied to the flattened region of skin between the eyebrows (the glabella) elicits an eyeblink, which is the most consistent component of the startle reflex, and which is easily accessible to measurement (e.g., Hoffman, Cohen, \& Stitt, 1981). The amplitude of these and other reflexes is determined in part by the sensory events that immediately precede the reflexeliciting stimulus (Buckland, Buckland, Jamieson, \& Ison, 1969; Graham, 1975; Hoffman \& Ison, 1980; Hoffman \& Searle, 1965, 1968; Hoffman \& Stitt, 1980; Hoffman \& Wible, 1969, 1970). In particular, when a relatively weak signal (e.g., a mild tone) precedes a more intense reflex-eliciting stimulus by an interval of approximately $100 \mathrm{msec}$, the amplitude of the elicited reaction is reduced. This phenomenon is called prestimulus reflex inhibition (Hoffman \& Ison, 1980; Ison \& Hoffman, 1983; Wu, Krueger, Ison, \& Gerrard, 1984).

The neural and functional bases of prestimulus inhibition are not yet fully understood, although the dynamics of the phenomenon have been extensively investigated (Hoffman \& Ison, 1980). It is clear that prestimulus inhibition is mediated by separate neural pathways that impinge upon the primary startle-elicitation circuit (Davis, Gendelman, Tischler, \& Gendelman, 1982; Leitner, Powers, Stitt, \& Hoffman, 1981). Such inhibitory path-

This research was supported in part by Grant HD 10511 to Howard S. Hoffman from the National Institutes of Health. We wish to thank Carol Fowler, Howard Hoffman, and Kevin McConkey for their comments during the preparation of this paper. The manuscript was prepared while Jacquelyn Cranney was at Dartmouth College. Requests for reprints should be sent to Jacquelyn Cranney, School of Psychology, University of New South Wales, P.O. Box 1, Kensington, N.S.W. 2033, Australia. ways may (Uhlrich, 1984) or may not (Leitner \& Cohen, in press) require cortical mediation, depending on the nature of the prestimulus. Prestimulus inhibition is neither the result of an orienting response to the prestimulus nor the result of conditioning of the prestimulus to the startleeliciting stimulus (Hoffman \& Ison, 1980; Wu et al., 1984). Prestimulus inhibition occurs on the first trial, and the prestimulus need only be at or near its detection threshold for measurable reflex inhibition to occur. As Wu et al. (1984) have argued, it appears that prestimulus inhibition is a fixed and obligatory consequence of all sensory stimuli, and the phenomenon is not readily affected by attentional variables (see Cohen, Cranney, \& Hoffman, 1983). These characteristics of prestimulus inhibition allow for the investigation of sensory processing independent of potentially confounding effects such as decreased attention and habituation. The current study investigated the reflex-inhibitory effects of relatively complex changes in an acoustic prestimulus.

The majority of previous investigations of reflex modification have employed unidimensional, steady-state pure tones or noise bands as the reflex-modifying event, and the nature of their inhibitory effects has been studied extensively (see Hoffman \& Ison, 1980, for a review). The effects of multidimensional reflex-modifying acoustic events, however, have received relatively little attention, despite the relevance that such analysis might have for an understanding of the effects of naturally occurring, patterned sounds. Previous research on the reflex-inhibitory effects of multidimensional stimuli has indicated that a brief gap (Ison, 1982; Ison \& Pinckney, 1983; Kellogg, Ison, \& Miller, 1983) or a shift (Stitt, Hoffman, Marsh, $\&$ Boskoff, 1974) in an otherwise continuous noise band can produce substantial response inhibition. Further, the amount of reflex inhibition is approximately a linear function of the size of the antecedent shift in frequency or in- 
tensity of the noise band (Marsh, Hoffman, Stitt, \& Schwartz, 1975).

The current research examined the reflex-inhibitory effects of a number of multidimensional acoustic events; in particular, it followed research by Cranney, Hoffman, and Cohen (1984). That research investigated the reflexmodifying effects of shifts and gaps in pure tones and found that a gap with a tonal frequency shift (gap-shift) was more inhibitory than a gap with no shift (gap/noshift), but no more inhibitory than the onset of a tone $150 \mathrm{msec}$ prior to the reflex-eliciting stimulus. The present experiments attempted to tease apart the factors involved in the different inhibitory effects of frequency and intensity modulations. Ison, Zuckerman, and Russo (1975) found that the inhibitory effects of individual stimulus elements summate in a linear fashion when combined; the studies presented here attempted to isolate the various components of gaps and frequency shifts and examine how they interacted as inhibitory stimuli. A gap in an otherwise continuous pure tone contains the potentially inhibitory components of two intensity modulations (i.e., an intensity decrement, a silent period, and an intensity increment), while a frequency shift in a continuously present tone contains the potentially inhibitory component of a frequency modulation from one level to another. A tone that involves both a gap and a frequency shift contains both intensity and frequency modulations. Given Ison et al.'s (1975) finding, we would expect that the more complex the stimulus, the more inhibition it should afford. Overall, the research attempted to extend information about the reflex modification effects of complex acoustic events, and to provide data on temporal and tonal frequency processing that might be useful to applied areas such as audiometry (Hoffman, Cohen, \& English, in press; Marsh, Hoffman, \& Stitt, 1978; Young \& Fechter, 1983).

\section{EXPERIMENT 1}

Cranney et al. (1984) found that a gap that involved a frequency shift led to more inhibition than did a gap with no frequency shift. Because other investigators (e.g., Marsh et al., 1975; Stitt et al., 1974) had found that a shift in a constant amplitude band of noise was inhibitory, Experiment 1 examined whether a shift in a pure tone was inhibitory, and compared its effect to that of a gap with a frequency shift. Therefore, the first experiment employed a condition that involved a frequency modulation but no intensity modulation (continuous shift), as well as gap/no-shift and gap-shift conditions (similar to those employed by Cranney et al., 1984). The hypothesis was tested that the continuous shift condition would be inhibitory, but that the gap-shift condition would produce greater inhibition, because it contained both intensity and frequency modulations.

\footnotetext{
Method

Subjects. Fourteen (13 female and 1 male) students at Bryn Mawr College participated as paid volunteers.
}

Apparatus. The research was conducted in an IAC double-wall, sound-treated (ambient noise level below $25 \mathrm{dBA}$ ) room that was suitably lighted and equipped with a rear-projection screen so that $35-\mathrm{mm}$ slides could be projected from the control area outside the room. A video camera and an intercom permitted continuous monitoring of the subject.

The acoustic stimuli were generated, shaped, amplified, and timed by Coulbourn programming modules, and were delivered to the subject through TDH-39 earphones fitted with MX-41/AR cushions. The earphones and test stimuli were calibrated using the 0 scale of a General Radio precision sound level meter (Model 1561-A), fitted with a P-7 microphone and ANSI Type 1 coupler. All intensities reported here are sound pressure level (SPL re $20 \mu \mathrm{Pa}$ ).

Glabella taps were delivered by a device that consisted of a miniature solenoid with a 5-cm-diam ball of silicone rubber securely fastened to its plunger. When the solenoid was activated, the ball was thrust forward with an impulse that, as measured with a ballistic pendulum, was equal to 0.95 times the voltage applied; see Marsh, Hoffman, and Stitt (1979) for a detailed description.

Eyeblinks were measured by a device that consisted of a miniature optical unit $(1 \times 0.5 \times 0.5 \mathrm{~cm})$ that contained an infrared lightemitting diode and a sensitive phototransistor pickup. The peak output of the eyeblink-monitoring device during the $150-\mathrm{msec}$ period that began with the onset of the 50 -msec tap was amplified and filtered electronically before being sent to a storage oscilloscope; see Marsh et al. (1979) for a detailed description.

The tap and eyeblink-monitoring devices were attached to a lightweight headband that was placed on the subject so that the silicone ball on the solenoid was approximately $3 \mathrm{~mm}$ away from the glabella and the eyeblink-monitoring device was in front of the subject's left eye, approximately $5 \mathrm{~mm}$ away from the ends of the eyelashes.

Stimulus conditions. Each subject was presented with five stimulus conditions (see Figure 1): (1) a tap with no prior or concurrent
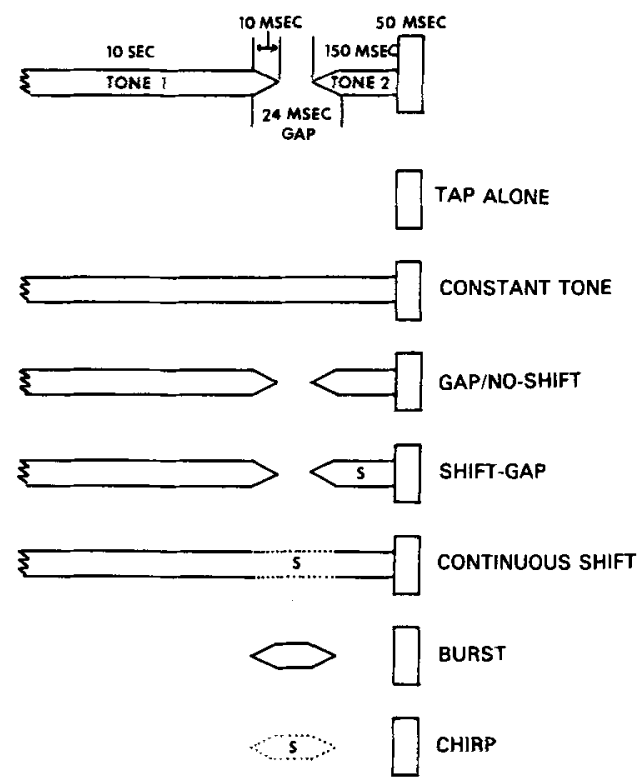

Figure 1. The general set of conditions used in this series of experiments (not to scale). The top configuration is the general prototype for the stimulus conditions. " $S$ " signifies a shift in frequency, and the dotted line indicates a frequency shift with no change in intensity. In Experiment 1, the tap alone, constant tone, gap/noshift, gap-shift, and continuous shift conditions were employed. In Experiment 2, the tap-alone, gap/no-shift, gap-shift, and continuous shift conditions were employed, with two different intensities for each of the tonal conditions. In Experiment 3, all stimulus conditions except the constant tone condition were employed. 
tonal stimulation (tap-alone condition); (2) a $10-\mathrm{sec}, 1.0-\mathrm{kHz}$ tone ending with the tap (constant tone condition); (3) a $10-\mathrm{sec}, 1.0-\mathrm{kHz}$ tone with a 4-msec silent period ending $150 \mathrm{msec}$ prior to the tap (gap/no-shift condition); (4) a $10-\mathrm{sec}, 1.75-\mathrm{kHz}$ tone in which a 4-msec silent period was followed by a frequency shift to $1.0 \mathrm{kHz}$ 150 msec prior to the tap (gap-shift condition); (5) a 10-sec, 1.75$\mathrm{kHz}$ tone in which a $24-\mathrm{msec}$ linear frequency shift to $1.0 \mathrm{kHz}$ ending $140 \mathrm{msec}$ prior to the tap (continuous shift condition). All tones were $70 \mathrm{~dB}$ in intensity with a rise-fall time of $10 \mathrm{msec}$ (including the rise-fall times that surrounded the 4-msec silent period, constituting a 24-msec gap duration).

The tap-alone condition was a glabella tap (produced by delivering a 16-V 50-msec pulse to the tap solenoid) in the absence of prior or concurrent acoustic stimulation. Responses in this condition were compared with responses when the tap was either accompanied or preceded by a given acoustic stimulus. The acoustic stimuli were artifact free, and their parameters were relevant to speech and consistent with the documented technology of reflex modification. Specifically, all tone onsets and offsets were moderately slow (i.e., linear rise/fall time $=10 \mathrm{msec}$ ) in order to avoid the acoustic transients (click-like sounds) that occur whenever a pure tone undergoes a rapid change in intensity and/or frequency (see Licklider, 1951 , for a detailed discussion of this problem); tonal frequencies were 1.0 and $1.75 \mathrm{kHz}$, which are within the range of normal speech and are easily discriminable from each other; and only a downward shift was employed since there is no differential effect for direction of frequency shift (Cranney et al., 1984). In tonal conditions containing a gap, a $10-\mathrm{sec}$ tone was followed by a number of critical events: a 10-msec fall in the intensity of the first tone was followed by $4 \mathrm{msec}$ of silence, and then the $10-\mathrm{msec}$ onset of the second tone. In all tonal conditions, the onset of the 50-msec tap coincided with the beginning of the tonal offset of $10 \mathrm{msec}$.

Procedure. Following informed consent procedures, the subjects were seated and fitted with the earphones and the headband that held the tap and eyeblink-monitoring devices. The subjects were told that they would receive various tones and taps while they were watching a series of color slides. They were told that we were measuring their blinks in reaction to the taps, but that they need not be concerned about them and that they should relax and enjoy the slides. Subjects received eight binaural presentations of each of the five stimulus conditions in a random order, with a variable intertrial interval (ITI; mean $=20 \mathrm{sec}$, range $=15$ to $25 \mathrm{sec}$ ). Each stimulus condition occurred once in each block of five trials in an order that varied across eight trial blocks.

\section{Results and Discussion}

The basic datum unit in these experiments was the mean amplitude of eyeblink across trials for each condition for each subject. Figure 2 shows the mean eyeblink amplitude for the five stimulus conditions. A one-way repeated measures analysis of variance indicated statistical significance $[F(4,52)=29.82, p<.05]$. Newman-Keuls analysis indicated that (1) eyeblink amplitudes in the tapalone and constant tone conditions were similar, and greater than the eyeblink amplitudes in all other conditions, and (2) eyeblink amplitudes in the gap-shift and continuous shift conditions were similar, and less than that in the gap/no-shift condition $(\mathrm{p}<.05$ in each case). The results support the prediction that the continuous shift condition would be inhibitory, but do not support the prediction that the gap-shift condition would produce greater inhibition than the continuous shift condition. In addition, this experiment indicated that a gap with a shift of $0.75 \mathrm{kHz}$, from 1.75 to $1.0 \mathrm{kHz}$, is more inhibitory than a gap with no shift. This extends Cranney et al.'s (1984)

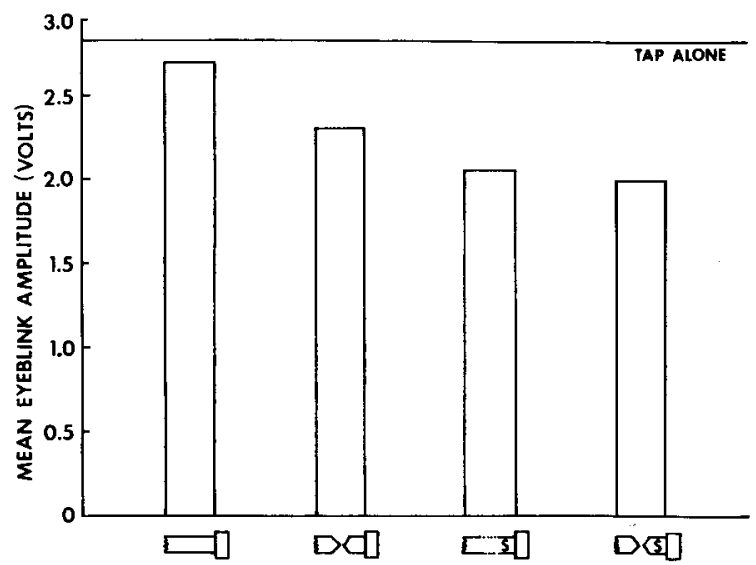

Figure 2. Mean amplitude of tap-elicited eyeblinks for each of the several stimulus conditions illustrated schematically below the horizontal axis of the figure. (The vertically oriented rectangles = the tap; the horizontally oriented rectangles = the tone. See Figure 1 for a detailed description. $S=$ shift in frequency; the dotted line $=$ frequency shift with no change in intensity. The horizontal line in the figure $=$ the mean amplitude of eyeblinks elicited by the tap without prior or concurrent acoustic stimulation.)

finding of a frequency shift advantage (i.e., more inhibition than gap/no-shift) with a $1-\mathrm{kHz}$, but not with a $0.25-\mathrm{kHz}$ shift. Therefore, the threshold for the frequency shift advantage must lie between a $0.25-$ and $0.75-\mathrm{kHz}$ shift with reference to a downward shift to $1.0 \mathrm{kHz}$.

\section{EXPERIMENT 2}

The finding of Experiment 1 that the gap-shift condition produced no greater inhibition than did the continuous shift condition could be explained in terms of a ceiling effect. Specifically, the inhibitory effect of an intensity or frequency modulation may increase as the intensity of the tone increases (e.g., Cranney, Cohen, \& Hoffman, 1985). Experiment 1 used a relatively high-intensity tone (70 dB) which may have led to a maximal amount of inhibition, so that the gap (although inhibitory in and of itself) could not add to the amount of inhibition in the gapshift condition. Accordingly, Experiment 2 employed two levels of tonal intensity, 50 and $75 \mathrm{~dB}$. If a ceiling effect was operative, the gap-shift and continuous shift conditions should produce equivalent amounts of inhibition at the high-intensity level, whereas the gap-shift condition should produce greater inhibition than the continous shift condition at the low-intensity level.

\section{Method}

Subjects and Apparatus. Eleven female students at Bryn Mawr College participated as paid volunteers. The apparatus was that used in Experiment 1.

Stimulus conditions and procedure. Each subject was presented with seven stimulus conditions (see Figure 1): (1) a tap without prior or concurrent tonal stimulation (tap-alone condition); (2) a 10-sec, $50-\mathrm{dB}, 1.0-\mathrm{kHz}$ tone with a $4-\mathrm{msec}$ silent period ending $150 \mathrm{msec}$ prior to the tap (50-dB gap/no-shift condition); (3) a 10-sec, 75$\mathrm{dB}, 1.0-\mathrm{kHz}$ tone with a $4-\mathrm{msec}$ silent period ending $150 \mathrm{msec}$ prior 


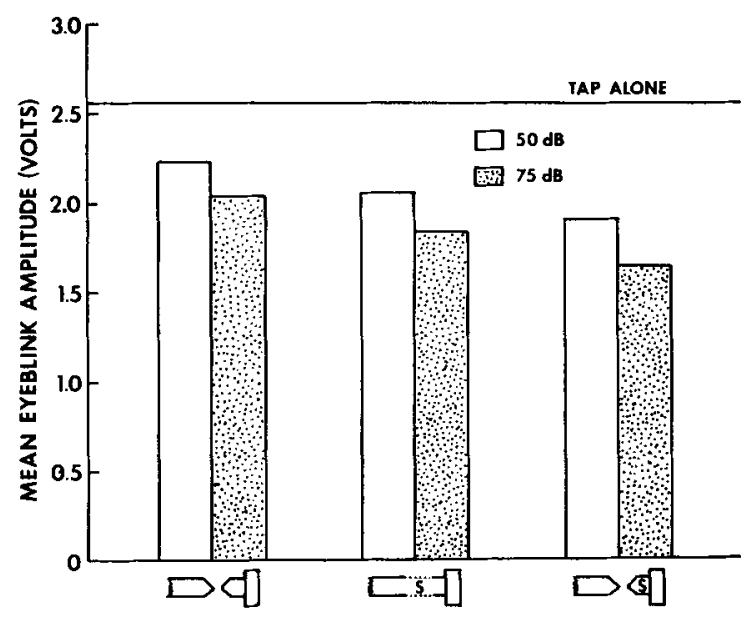

Figure 3. Mean amplitude of tap-elicited eyeblinks for each of the several stimulus conditions illustrated schematically below the horizontal axis of the figure. (The vertically oriented rectangles = the tap; the horizontally oriented rectangles = the tone. See Figure 1 for a detailed description. $S$ = shift in frequency; the dotted line $=$ frequency shift with no change in intensity. The horizontal line in the figure $=$ the mean amplitude of eyeblinks elicited by the tap without prior or concurrent acoustic stimulation.)

to the tap (75-dB gap/no-shift condition); (4) a 10-sec, 50-dB, 1.75$\mathrm{kHz}$ tone in which a 4-msec silent period was followed by a frequency shift to $1.0 \mathrm{kHz} 150 \mathrm{msec}$ prior to the tap (50-dB gap-shift condition); (5) a 10-sec, 75-dB, 1.75-kHz tone in which a 4-msec silent period was followed by a frequency shift to $1.0 \mathrm{kHz} 150 \mathrm{msec}$ prior to the tap (75-dB gap-shift condition); (6) a 10-sec, 50-dB, $1.75-\mathrm{kHz}$ tone in which a $24-\mathrm{msec}$ linear frequency shift to $1.0 \mathrm{kHz}$ ended $140 \mathrm{msec}$ prior to the tap (50-dB continuous shift condition); and (7) a 10-sec, 75-dB, 1.75-kHz tone in which a 24-msec linear frequency shift ended $150 \mathrm{msec}$ prior to the tap (75-dB continuous shift condition). All tones had rise/fall times of $10 \mathrm{msec}$.

Procedurally, the study paralleled Experiment 1. Each stimulus condition occurred once in each block of seven trials in an order that varied across seven-trial blocks.

\section{Results and Discussion}

Figure 3 shows the mean amplitude of elicited eyeblinks in each of the seven stimulus conditions. A one-way repeated measures analysis of variance indicated statistical significance $[F(6,60)=13.12, p<.05]$. A Dunnett's test $(\mathrm{p}<.05)$ indicated that all tonal conditions produced responses that were significantly lower than that produced in the tap-alone condition ( $p<.05$ in each case). A subsequent two-way (tonal intensity $\times$ tonal condition) repeated measures analysis of variance revealed a significant main effect for intensity $[\mathrm{F}(1,50)=21.28, \mathrm{p}<.05$; $50-\mathrm{dB} M=2.11,75-\mathrm{dB} M=1.88]$, a significant main effect for tonal condition $[F(2,50)=13.8, p<.05]$, and a nonsignificant interaction effect. Newman-Keuls analysis revealed that the responses in the gap-shift ( $M=$ $1.83)$ and continuous shift $(M=1.98)$ conditions were similar and were significantly less than the response in the gap/no-shift condition $(M=2.17 ; p<.05$ in each case). Thus, the finding of Experiment 1 that the responses in the gap-shift and continuous shift conditions were similar, and less than in the gap/no-shift condition, was replicated in this experiment at two different intensity levels. In addition, the finding that the higher tonal intensity led to a greater amount of inhibition is consistent with a similar result obtained in rats (Cranney et al., 1985). Given these findings, the similar response amplitudes in the gap-shift and continuous shift conditions in Experiment 1 cannot be attributed to a ceiling effect in inhibition.

\section{EXPERIMENT 3}

Experiment 3 examined the relative inhibitory effects of intensity and frequency modulations outside the continuous tone context. That is, a brief tonal burst which involved two intensity modulations (the rise and fall of the tone), was compared with a "chirp," which involved two intensity modulations and a frequency modulation (Mattingly, Liberman, Syrdal, \& Halwes, 1971). The issue addressed was whether the frequency shift of the chirp would result in any additional inhibitory effect. In addition, the inhibitory effects of the short-duration tones were compared with the inhibitory effects of their long-duration complements (gap/no-shift, gap-shift, and continuous shift), in order to determine the differential effects of tonal duration and tonal presence at different periods prior to the reflex-eliciting stimulus (see Figure 1).

\section{Method}

Subjects and Apparatus. Twelve (9 female and 3 male) students at Bryn Mawr College participated as paid volunteers. The apparatus was that used in Experiments 1 and 2.

Stimulus conditions and procedure. Each subject was presented with six stimulus conditions (see Figure 1): (1) a tap without prior or concurrent tonal stimulation (tap-alone condition); (2) a 10-sec, $1.0-\mathrm{kHz}$ tone with a 4-msec silent period ending $150 \mathrm{msec}$ prior to the tap (gap/no-shift condition); (3) a 10-sec, $1.75-\mathrm{kHz}$ tone in which a 4-msec silent period was followed by a frequency shift to $1.0 \mathrm{kHz} 150 \mathrm{msec}$ prior to the tap (gap-shift condition); (4) a 10 sec, $1.75-\mathrm{kHz}$ tone in which a $24-\mathrm{msec}$ linear frequency shift to $1.0 \mathrm{kHz}$ ended $140 \mathrm{msec}$ prior to the tap (continuous shift condition); (5) A 24-msec, 1.0-kHz tone burst, which ended $140 \mathrm{msec}$ prior to the tap and consisted of a 10-msec rise, $4 \mathrm{msec}$ of steady tone, and a 10-msec fall (burst condition); (6) a 24-msec chirp, which ended $140 \mathrm{msec}$ prior to the tap and consisted of a 24-msec linear frequency transition from 1.75 to $1 \mathrm{kHz}$, including a 10-msec rise, $4 \mathrm{msec}$ of constant amplitude tone, and a 10-msec fall (chirp condition). All tones were $65 \mathrm{~dB}$ in intensity (an intermediate level between the 50 and $75 \mathrm{~dB}$ used in Experiment 2), with rise/fall times of $10 \mathrm{msec}$.

Procedurally, the study paralleled Experiments 1 and 2. Each stimulus condition occurred once in a block of six trials, in an order that varied across eight trial blocks.

\section{Results and Discussion}

Figure 4 shows the mean eyeblink amplitude for the six stimulus conditions. A one-way repeated measures analysis of variance indicated statistical significance $[F(5,55)$ $=7.76, \mathrm{p}<.05]$. Newman-Keuls analysis indicated that responses in all tonal conditions were significantly less than that in the tap-alone condition; moreover, the gap- 


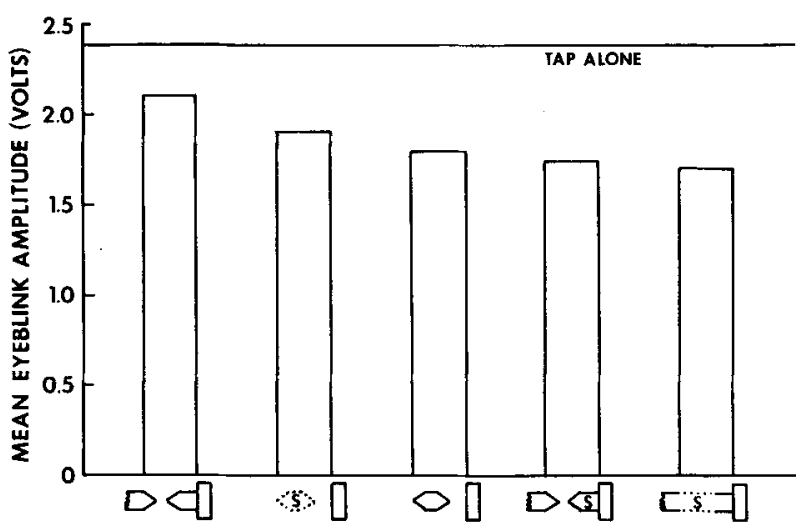

Figure 4. Mean amplitude of tap-elicited eyeblinks for each of the several stimulus conditions illustrated schematically below the horizontal axis of the figure. (The vertically oriented rectangles = the tap; the horizontally oriented rectangles = the tone. See Figure 1 for a detailed description. $S=$ shift in frequency; the dotted line $=$ frequency shift with no change in intensity. The horizontal line in the figure $=$ mean amplitude of eyeblinks elicited by the tap without prior or concurrent acoustic stimulation.

shift and continuous shift conditions produced similar amounts of inhibition that were significantly lower than that produced by the gap/no-shift condition $(\mathrm{p}<.05$ in each case). Responses in the chirp and burst conditions were similar, and no different from any of the longduration tonal conditions.

These findings indicate that the frequency shift does not add anything to the inhibitory effect of a short-duration tone. In addition, the amount of inhibition produced by the short-duration tones was similar to that produced by the continuous shift and gap-shift conditions. These findings are consistent with our previous investigations (Cranney, 1983; Cranney et al., 1984; Cranney et al., in press). The amount of inhibition produced by the chirp and burst, however, was also similar to that produced by the gap/noshift condition. Hence, the inhibitory effects of the shortduration stimuli employed in the current study appear to be intermediate between the inhibitory effects of the longduration shift conditions and the long-duration gap/noshift condition.

\section{GENERAL DISCUSSION}

This series of experiments investigated the reflexinhibitory effects of different multidimensional stimuli. Experiment 1 found that a frequency modulation in an otherwise continuous pure tone led to the same amount of inhibition as did a frequency shift following an intensity decrement (gap) in a pure tone; further, this amount of inhibition was greater than that produced by a gap with no frequency shift. Experiment 2 replicated this pattern of findings at two different tonal intensity levels, and showed that a lower tonal intensity led to less inhibition. Experiment 3 indicated that a 24-msec constant tonal frequency burst and a 24-msec shifting tonal frequency chirp, when presented 164 msec prior to the glabella tap, led to an equivalent amount of inhibition; further, this amount of inhibition was not significantly different from that produced by either the gap/no-shift condition or the two long-duration tonal shift conditions (continuous shift and gap-shift).

These findings support the conclusions reached in our previous investigations (Cranney et al., 1984, in press), that the amount of inhibition engendered by a complex acoustic event is not merely a function of the inhibitory effects of the different elements that make up that event. For instance, Experiment 1 found that the shift-gap condition (which contains the potentially inhibitory elements of intensity decrement, increment, and frequency shift) was no more inhibitory than the continuous shift condition (which contains the potentially inhibitory element of frequency shift only). In addition, Experiment 3 showed that the frequency shift did not add any inhibitory effect to a short-duration tone.

The difference between the shift-gap and gap/no-shift conditions can be explained at a neurophysiological level in terms of differential activity in central auditory pathways (see Cranney et al., 1984) or at a psychophysical level in terms of differential gap resolution with different tonal frequencies. Fitzgibbons $(1983,1984)$ reported that gap threshold decreased systematically with increased tonal frequency to about $5 \mathrm{kHz}$. The higher frequency component in the shift condition of this study may have enhanced the detectability of the gap in the shift condition. This could result in greater reflex inhibition, just as longer (and more detectable) gaps result in greater reflex inhibition (Cranney et al., in press; Ison, 1982; Ison \& Pinckney, 1983). Future research could test this notion by employing a parallel psychophysical gap-detection procedure.

The finding of equivalent reflex inhibition for the continuous shift and shift-gap conditions in this study is not easily understood at either the physiological or psychophysical levels. At the physiological level, the effect may be explained in terms of the differential amount of change in patterns of neuronal firing of onset and offset detectors and of frequency-specific auditory neurons (Kiang, 1975; Whitfield, 1978). This level of explanation remains somewhat speculative, however. At the psychophysical level, profile analysis (Green, 1983; Green, Mason, \& Kidd, 1984) may provide a basis for explanation; in particular, a globally based mechanism, which makes comparisons across a wide range of frequencies, could be equally evoked by both the gap-shift and continuous shift conditions. Future research could employ Green et al.'s (1984) stimuli in the context of a reflexinhibitory paradigm in order to explore this possibility.

The finding of equivalent reflex inhibition for the shortduration (burst, chirp) and long-duration gap/no-shift conditions in this study contrasts with Cranney et al.'s (1984) report that a short-duration stimulus, a $150-\mathrm{msec}$ tone which onset $150 \mathrm{msec}$ prior to the tap, led to greater inhibition than did the gap/no-shift condition. It is possible that a short-duration tone must maintain a constant am- 
plitude for a minimum amount of time (i.e., more than the $4 \mathrm{msec}$ employed in the present study and as much as the 140 msec employed by Cranney et al., 1984) in order to produce significantly greater inhibition than the gap/no-shift condition. This suggestion is supported by psychophysical findings that absolute and differential thresholds decrease rapidly between 4 and $100 \mathrm{msec}$ (Green et al., 1984; Watson \& Gengel, 1969). Thus, the 150 -msec onset stimulus of Cranney et al. (1984) may have been more detectable, and hence had a stronger inhibitory effect than the 24-msec stimuli employed in the current study. Future studies should directly assess the relevance of the stimulus duration factor.

The gap/no-shift condition itself contains a $150-\mathrm{msec}$ "onset" component (Tone 2), which presumably has a strong reflex-inhibitory effect. However, the preceding 10-sec component (Tone 1) may decrease the potential inhibitory effect of Tone 2 , possibly by producing a tempory threshold shift (Jerger, 1955).

The inhibitory effects of the two short-duration stimuli (burst, chirp) were equivalent in this study. Psychophysical studies (e.g., Watson \& Gengel, 1969) have reported that the form of the temporal integration function changes with different frequencies; however, no significant differences exist between the two frequencies ( 1 and $1.75 \mathrm{kHz}$ ) employed in the current study. Future research could employ frequencies known to produce different temporal integration functions (e.g., 0.25 and $4 \mathrm{kHz}$ ).

In summary, the current series of experiments has extended knowledge of the reflex inhibitory effects of complex acoustic events, and has provided us with some insights as to the possible mechanisms underlying reflex inhibition in general and the processing of auditory prestimuli in particular. Moreover, such information can be utilized in reflex-inhibitory procedures that have been specially developed for the assessment of auditory capacity (Hoffman et al., in press; Marsh et al., 1978; Young \& Fechter, 1983).

\section{REFERENCES}

Buckland, G., Buckland, J., Jamieson, C., \& Ison, J. R. (1969). Inhibition of the startle response to acoustic stimulation produced by visual presentation. Joumal of Comparative and Physiological Psychology, 67, 493-496.

Cohen, M. E., Cranney, J., \& Hoffman, H. S. (1983), Motor and cognitive factors in the modification of a reflex. Perception \& Psychophysics, 34, 214-220.

CRANNEY, J. (1983). Tonal frequency shifis and gaps in acoustic stimulation as reflex inhibitory events. Unpublished doctoral dissertation, Bryn Mawr College, Bryn Mawr, PA.

Cranney, J., Cohen, M., \& Hoffman, H. S. (1985). Acoustic startle reflex in the rat: Impact of baseline tonal intensity on the inhibitory effects of a gap. Manuscript submitted for publication.

Cranney, J., Cohen, M. E., \& Hoffman, H. S. (in press). Reflex modification in the rat: The inhibitory effects of intensity and frequency changes in steady tones. Journal of Experimental Psychology: Animal Behavior Processes.

Cranney, J., Hoffman, H. S., \& Cohen, M. E. (1984). Tonal frequency shifts and gaps in acoustic stimulation as reflex-inhibitory events. Perception \& Psychophysics, 35, 165-172.
Davis, M., Gendelman, D. S., Tischler, M. D., \& Gendelman, P. M. (1982). A primary acoustic startle circuit: Lesion and stimulation studies. Journal of Neuroscience, 2, 791-805.

Fitzgibions, P. J. (1983). Temporal gap detection in noise as a function of frequency, bandwidth, and level. Journal of the Acoustical Society of America, 74, 67-72.

FitzGibBons, P. J. (1984). Temporal gap resolution in narrow-band noises with center frequencies from $6000-14000 \mathrm{~Hz}$. Journal of the Acoustical Society of America, 75, 566-569.

GrahaM, F. K. (1975). The more or less startling effects of weak prestimulation. Psychophysiology, 12, 238-248.

Green, D. M. (1983). Profile analysis. American Psychologist, 38, 133-142.

Green, D. M., Mason, C. R., \& KidD, G., JR. (1984). Profile analysis: Critical bands and duration. Journal of the Acoustical Society of America, 75, 1163-1167.

Hoffman, H. S., Cohen, M. E., \& English, L. (in press). Reflex modification by acoustic signals in newborn infants and in adults: $\mathbf{A}$ new approach to the objective assessment of hearing in difficult to test subjects. Journal of Experimental Child Psychology.

Hoffman, H. S., Cohen, M. E., \& STrT , C. L. (1981). Acoustic augmentation and inhibition of the human eyeblink. Journal of Experimental Psychology: Human Perception and Performance, 7, 1357-1362.

HoffmaN, H. S., \& Ison, J. R. (1980). Reflex modification in the domain of startle: I. Some empirical findings and their implications for how the nervous system processes sensory input. Psychological Review, 87, 175-189.

Hoffman, H. S., \& Searle, J. L. (1965). Acoustic variables in the modification of startle reaction in the rat. Journal of Comparative and Physiological Psychology, 60, 53-58.

Hoffman, H. S., \& SEARLE, J. (1968). Acoustic and temporal factors in the evocation of startle. Joumal of the Acoustical Society of America, 43, 269-282.

HofFmaN, H. S., \& STITT, C. L. (1980). Inhibition of the glabella reflex by monaural and binaural stimulation. Journal of Experimental Psychology: Human Perception and Performance, 6, 769-776.

HofFMAN, H. S., \& WIBLE, B. (1969). Temporal parameters in startle facilitation by steady background signals. Journal of the Acoustical Society of America, 45, 7-12.

HofFMAN, H. S., \& WIBLE, B. L. (1970). Role of weak signals in acoustic startle. Journal of the Acoustical Society of America, 47, 489-497.

Ison, J. R. (1982). Temporal acuity in auditory function in the rat: Reflex inhibition by brief gaps in noise. Journal of Comparative and Physiological Psychology, 96, 945-954.

Ison, J. R., HofFMAN, H. S. (1983). Reflex modification in the domain of startle: II. The anomalous history of a robust and ubiquitous phenomenon. Psychological Bulletin, 94, 3-17.

Ison, J. R., \& PINCKNey, L. A. (1983). Reflex inhibition in humans: Sensitivity to brief silent periods in white noise. Perception \& Psychophysics, 34, 84-88.

Ison, J. R., ZuCKerman, M., \& Russo, J. M. (1975). Combination rules for inhibitory stimuli. Joumal of Experimental Psychology: Animal Behavior Processes, 1, 318-325.

JERGER, J. F. (1955). Influence of stimulus duration on pure-tone threshold during recovery from auditory fatigue. Joumal of the Acoustical Society of America, 27, 121-124.

KellogG, C., Ison, J. R., \& MilleR, R. K. (1983). Auditory temporal resolution in rats: Effect of prenatal diazepam exposure. Psychopharmacologia, 79, 332-337.

KIANG, N.Y.S. (1975). Stimulus representation in the discharge patterns of auditory neurons. In E. L. Eagles (Ed.), The nervous system: Vol. 3. Human communication and its disorders. New York: Raven Press.

Landis, C., Hunr, W. A. (1939). The startle pattern. New York: Farrar \& Rinehart.

LEITNER, D. S., \& COHEN, M. E. (in press). The role of the inferior colliculus in inhibition of acoustic startle in the rat. Physiology \& Behavior.

Leitner, D. S., Powers, A. S., Stitt, C. L., \& Hoffman, H. S. (1981). Midbrain reticular formation involvement in the inhibition 
of acoustic startle. Physiology \& Behavior, 26, 259-268.

LiCKLIDER, J. C. R. (1951). Basic correlates of the auditory stimulus. In S. S. Stevens (Ed.), Handbook of experimental psychology. New York: Wiley.

Marsh, R. R., Hoffman, H. S., \& STITt, C. L. (1978). Reflex inhibition audiometry: A new objective technique. Acta Otolaryngologica, 85, 336-341.

Marsh, R. R. Hoffman, H. S., \& STITT, C. L. (1979). Eyeblink elicitation and measurement in the human infant. Behavior Research Methods \& Instrumentation, 11, 498-502.

Marsh, R., Hoffman, H. S., Stitt, C. L., \& Schwartz, G. M. (1975). The role of small changes in the acoustic environment in modifying the startle reflex. Journal of Experimental Psychology: Animal Behavior Processes, 1, 235-244.

Mattingly, I. G., Liberman, A. M., Syrdal, A., \& Halwes, T. (1971). Discrimination in speech and nonspeech modes. Cognitive Psychology, 2, 131-157.

StitT, C. L., Hoffman, H. S., Marsh, R., \& BoskofF, K. J. (1974). Modification of the rat's startle reaction by an antecedent change in the acoustic environment. Journal of Comparative and Physiological Psychology, 86, 826-836.

UhLRICH, D. J. (1984, April). Spatial vision in humans assessed by inhibition of the blink reflex. In L. D. Fechter (Chair), Reflex modification: A simple objective approach to infant audiometry, adult psychophysics and animal behavioral toxicology. Symposium conducted at the 55th Annual Meeting of the Eastern Psychological Association, Baltimore.

WAtson, C. S., Gengel, R. W. (1969). Signal duration and signal frequency in relation to auditory sensitivity. Journal of the Acoustical Society of America, 46, 989-997.

Whitfield, J. C. (1978). The neural code. In E. C. Carterette \& M. P. Freidman (Eds.), Handbook of perception,: Vol. IV. Hearing. New York, Academic Press.

Wu, M.F., Krueger, J., Ison, J. R., \& Gerrard, R. L. (1984). Startle reflex inhibition in the rat: Its persistence after extended repetition of the inhibitory stimulus. Journal of Experimental Psychology, 10, 221-228.

Young, J. S., \& FeChTER, L. D. (1983). Reflex inhibition procedures for animal audiometry: A technique for assessing ototoxicology. Journal of the Acoustical Society of America, 73, 1686-1693.

(Manuscript received May 18, 1984; accepted for publication November 30, 1984.) 